\title{
Cutaneous leishmaniasis: an emerging health risk in Sri Lanka
}

\author{
Much work needs to be done regarding specific parasite identification, epidemiology, \\ clinical diagnosis and prevention.
}

In Sri Lanka leishmaniasis has been viewed as an exotic disease linked with foreign travel or as a disease of Indian immigrants. Local transmission was considered nonexistent although the tropical climate with high humidity favours the breeding of sandflies, the vectors of this disease.

Since the early 1990s this view changed with the recognition of autochthonous cutaneous leishmaniasis. The first documented case in 1992 was a young man from Ambalantota who initially gave a history of contact with dry zone jungle but later denied this history (1). This was followed a few years later by a number of cases from different parts of the island. The second and third case reports were from Mahiyangana (2) and Badulla (Seneviratne JKK. Personal communication). The later cases were from Pannala, Rajangana and Pottuvil (3). All were in young men presenting as cutaneous lesions in exposed body parts and with behaviour activities related to the scrub jungle. In 1996 a study done to assess disease prevalence in an area with potential risk of exposure using the leishmanin skin test and clinical examination in schoolchildren, failed to show wide prevalence. Of the 253 children examined, in the Yalwela School, close to Mahiyangana, none were leishmanin positive, nor was there clinical evidence of the disease. Two of the children tested with leishmanin, were positive. Dr. Luigi Gradoni supplied leishmanin for this study.

With increased awareness among dermatologists, more cases were detected, especially in soldiers in the north and east. A few cases were also seen in women who had exposure to scrub jungle. In a recently reported series of six cases in permanent residents of Uva, one was of concern as the lesion was recurrent and resistant to cryotherapy (4).

\section{Epidemiological aspects}

Leishmaniasis is currently of global concern because of its high risk in military operations, international travel and its co-existence with HIV infection $(5,6)$. Several countries have experienced epidemics, including the south Asian countries Nepal, Bangladesh and India $(7,6)$. The disease is caused by several species of protozoans of the genus Leishmania. They cause a wide spectrum of clinical manifestations varying from self-healing cutaneous lesions (CL) to disseminated visceral disease (VL) and disfiguring mucocutaneous lesions.

The epidemiology varies widely ranging from enzootic disease with sporadic cases in humans, to rural zoonosis with rodents as reservoir hosts. It could be an urban zoonosis with dogs as important reservoir hosts, whereas the visceral leishmaniasis in India and east Africa is an anthroponotic with human-to-human transmission independent of reservoir hosts.

All leishmaniases are transmitted by different species of sandflies. The sandfly fauna of Sri Lanka has not been adequately studied. The few studies available indicate that the common sandfly is Phlebotomus argentipes, widely distributed in the island, and anthropophilic in the highlands $(9,10)$. This is the vector of $L$ donovani, the aetiological agent of VL (kala-azar) in India. The only other sandfly of potential vector status recorded locally is $P$ stentoni, a jungle species feeding on wild rodents (11). The absence of classical kala-azar in Sri Lanka is attributed to morphological variations in the local $P$ argentipes.

A retrospective study of case reports shows evidence, although not conclusive, of infection with $L$ donovani or a donovani-like parasite in Sri Lanka. In 1904, Castellani reported LD bodies from the spleen at post-mortem in a 20year old man in whom splenomegaly was clinically absent (12). In 1960 a case of post kala-azar dermal leishmaniasis was reported in a patient from Vanuniya, but local infection was not considered, as there was a doubt whether the patient was an illegal immigrant from India (13). In 1967 an English girl was diagnosed with classical VL on return to the UK after spending a few months in Sri Lanka. As the patient had brief stops in the Middle East and in Mediterranean countries during her travel, infection acquired elsewhere could not be excluded (14). In 1991, an HIV positive homosexual was diagnosed as VL within one month of his return from Sri Lanka (15). Although initially he was thought to have acquired the infection in Sri Lanka, later this was in doubt, as a detailed travel history was not available. Leishmaniasis is not known to occur in dogs in Sri Lanka, but in 1994, a German Shepherd dog from Hindagala, Kandy, taken to Geneva, developed dermatitis around the nostril and was diagnosed on serology as leishmaniasis (Dissanaike AS. Personal communication).

The question arises whether this disease emergence is due to recent introduction of the parasite with Middle East returnees or merely recognition of an existing disease.

Although cases of cutaneous leishmaniasis were reported from Middle East returnees in the 1980s (16), the vectors of classical CL are not known to be present here. Furthermore, the distribution of local cases throughout the dry zone is unlike that of a recently introduced disease. It is more likely that this is a recent recognition with increased awareness and increased risk of exposure of the population with jungle clearing, population shifts and the military activities in the north and east. Thus the epidemiology of cutaneous leishmaniasis in Sri Lanka at present 
indicates a zoonotic infection in the scrub jungle associated with wild rodents or canids as reservoir hosts.

\section{Future needs}

The current evidence points to the parasite being a zoonotic $L$ tropica, a non-visceralising $L$ donavani variant, or else, an entirely new species. Both the parasite and the vector require further study. The parasite needs to be specifically identified with isoenzyme and DNA analysis. A major breakthrough was the recent successful culturing of the parasite from a local case (Perera J. Personal communication). There is also much work to be done to resolve the epidemiology of leishmaniasis in Sri Lanka.

For solidiers in the north and east it is an occupational hazard, and effective repellents to ward off sandfly bites is necessary. The medical profession, particularly the general practitioners, needs to be aware of the clinical presentations. Although lesions respond well to cryotherapy, and are usually self-limiting with development of good celluar immunity, complications can occur (4), and specific drugs such as pentavalent antimony compounds should be available for treatment.

\section{References}

1. Athukorale DN, Seneviratne JKK, Ihalamulla RL, Premaratne UN. Locally acquired cutaneous leishmaniasis in Sri Lanka. Journal of Tropical Medicine and Hygiene 1992; 95: 432-3.

2. Seneviratne JKK, Siriwardena S, Ratnatunga N, Wijesundera MdeS. Locally acquired cutaneous leishmaniasis from central Sri Lanka: a case report. Kandy Medical Journal 1995; 4: 54-6.

3. Naotunne TDS, Ihalamulle RL, Kumarasinghe P, Amerasekera LR, Wijesundera MdeS. Proceedings of the Sri Lanka Association for the Advancement of Science 1999; p 21. (abstract).

4. Seneviratne JKK. Locally acquired cutaneous leishmaniasis - the
Uva experience. Sri Lanka College of Dermatologists, Annual Academic Sessions, NovemberlOQO. p 10. (abstracts).

5. Desjeux P. Leishmania and HIV in gridlock $W H O / C T D / L E I S H$ 98.9 Add.1; UNAIDS/98.23. WHO and UNAIDS, Geneva, 1998.

6. WHO. Leishmaniasis control home page. March 21,2001: <http://www.who.int/emc/diseases/leish/index.html> (30.06.2001).

7. Bora D. Epidemiology of visceral leishmaniasis in India. National Medical Journal of India 1999; 12: 62-8.

8. Kumar R, Kumar R, Chowdhury RK, Pai K, Mishra CP et al kala-azar epidemic in Varanasi district, India. Bulletin of the World Health Organization 1999; 77: 371-4.

9. Carter HF, Antonipulle P. Observations on sandflies (Phlebotomus) in Delft island in north Ceylon. Annals of Tropical Medicine and Parasitology 1949; 43: 62-73.

10. Lane RP. Pile MM, Amerasinghe FP. Anthropophagy and aggregation behaviour of sandfly Phlebotomus agentipes in Sri Lanka. Medical and Veterinary Entomology 1990; 4: 79-88.

11. Lewis DJ. The phlebotamine sandflies (Diptera: Psychodidae) of the oriental region. Bulletin of the British Museum of Natural History (Entomology) 1978; 37: 217-343.

12. Castellani A. Leishmania donovanx in Ceylon. Jouranl of Tropical Medicine 1904; 10: 262.

13. Dissanaike AS. Parasitic zoonoses with special reference to Sri Lanka. In: Elizabeth U Canning Ed. Parasitological Topics. Society of Protozoologists, Kansas USA: Allen Press Inc., 1981; 78-85.

14. Chapman RLK. Visceral leishmaniasis in an English girl. Proceedings of the Royal Society of Medicine 1973; 66: 1110.

15. Fenske S, Stellbrink HJ, Albrecht H, Greten H. Visceral leishmaniasis in an HIV infected patient: clinical features and response to treatment. Klinische Wochenscrift 1991; 69: 793-6.

16. Naotunne TdeS, Rajakulendran S, Abeywickrema W, Kulasiri CdeS, Perera J. Tropical and Geographical Medicine 1990; 42: $72-4$.

Manel de S Wijesundera, Professor of Parasitology, Faculty of Medicine, University of Peradeniya, Sri Lanka. (E-mail: $\quad$ wiiem@sltnet.lk) 